OPEN ACCESS

Edited by:

Carlo Perricone,

Sapienza University of Rome, Italy

Reviewed by:

Adriana Karina Chavez-Rueda,

Mexican Social Security Institute

(IMSS), Mexico

Fernando E. Figueroa,

University of the Andes, Chile

${ }^{*}$ Correspondence:

Donghua Xu

flower322@163.com

Shushan Yan

yanshushan@163.com

${ }^{\dagger}$ These authors have contributed equally to this work and share first authorship

Specialty section:

This article was submitted to

Autoimmune and

Autoinflammatory Disorders,

a section of the journal

Frontiers in Immunology

Received: 25 May 2021

Accepted: 23 August 2021

Published: 16 September 2021

Citation:

Yang C, Sun J, Tian Y, Li H, Zhang L, Yang J, Wang J, Zhang J, Yan S and Xu D (2021) Immunomodulatory

Effect of MSCs and MSCsDerived Extracellular Vesicles in Systemic Lupus Erythematosus.

Front. Immunol. 12:714832. doi: 10.3389/fimmu.2021.714832

\section{Immunomodulatory Effect of MSCs and MSCs-Derived Extracellular Vesicles in Systemic Lupus Erythematosus}

\author{
Chunjuan Yang ${ }^{1,2 \dagger}$, Jianmei Sun ${ }^{3 \dagger}$, Yipeng Tian ${ }^{4 \dagger}$, Haibo $\mathrm{Li}^{2 \dagger}$, Lili Zhang ${ }^{2}$, \\ Jinghan Yang ${ }^{1,2}$, Jinghua Wang ${ }^{1,2}$, Jiaojiao Zhang ${ }^{2}$, Shushan $\mathrm{Yan}^{5 *}$ and Donghua $\mathrm{Xu}^{1,2^{*}}$ \\ ${ }^{1}$ Department of Rheumatology of the First Affiliated Hospital, Weifang Medical University, Weifang, China, ${ }^{2}$ Central \\ Laboratory of the First Affiliated Hospital, Weifang Medical University, Weifang, China, ${ }^{3}$ Department of Chemistry, School of \\ Applied Chemistry, Food and Drug, Weifang Engineering Vocational College, Qingzhou, China, ${ }^{4}$ Material Procurement Office \\ of the First Affiliated Hospital, Weifang Medical University, Weifang, China, ${ }^{5}$ Department of Gastrointestinal and Anal \\ Diseases Surgery of the Affiliated Hospital, Weifang Medical University, Weifang, China
}

Systemic lupus erythematosus (SLE) is a common autoimmune connective tissue disease with unclear etiology and pathogenesis. Mesenchymal stem cell (MSC) and MSC derived extracellular vesicles (EVs) play important roles in regulating innate and adaptive immunity, which are involved in many physiological and pathological processes and contribute to the immune homeostasis in SLE. The effects of MSCs and EVs on SLE have been drawing more and more attention during the past few years. This article reviews the immunomodulatory effects and underlying mechanisms of MSC/MSC-EVs in SLE, which provides novel insight into understanding SLE pathogenesis and guiding the biological therapy.

Keywords: mesenchymal stem cells, extracellular vesicles, exosome, systemic lupus erythematosus, immunity

\section{INTRODUCTION}

SLE is a systemic autoimmune disease with multiple organs and multiple systems damages. It is characterized by abnormal activation of immune cells, abundant production of pathogenic autoantibodies and immune complexes deposition (1). The etiology and pathogenesis of SLE are complex and accompanied by immune disorders including abnormal proliferation, differentiation, activation and dysfunction of $\mathrm{T}$ cells, mononuclear-macrophage cells as well as $\mathrm{B}$ cells. Long term autoimmune disorders and sustained inflammation eventually cause tissue and organ damages $(2,3)$. Lupus nephritis is the most common and severe organ injury in SLE (4). At present, glucocorticoids and immunosuppressants are traditional treatments for SLE. However, there are still many refractory patients who are difficult to achieve clinical remission with high mortality. It brings a great economic burden and psychological pressure to SLE patients (5). As a result, investigating the optimal treatment strategy for SLE patients is still an urgent problem to be solved. Here, we provide an updated review of currently available information regarding dysregulated immune cells and mechanical molecules involved in SLE pathogenesis, which would be promising for investigating new biological approaches to SLE treatment. 
Mesenchymal stem cells (MSCs) are pluripotent stem cells that are widely distributed in human body, such as bone marrow (BM) (6), umbilical cord (UC) (7), umbilical cord blood (UCB) (8), peripheral blood (9), placenta (PL) (10), adipose tissues (AT) (11), and dental pulp (DP) (12). It has been demonstrated that MSCs derived EVs possess strong biological activity similar to MSCs (13). MSCs-EVs exert immunomodulatory effects by inducing immune cells differentiation into cells with more anti-inflammatory or tolerant phenotype (14). MSC-EVs promote the chemotaxis of anti-inflammatory noncoding RNAs towards injured tissues and participate in regulating inflammatory and immune response to better enhance the healing process (15). Bone marrow derived mesenchymal stem cells (BM-MSCs) are found to suppress the proliferation of cancer cells and induced dormant states (16). MSCs have selfrenewal, migration and immunosuppression functions under physiological conditions. However, some MSCs are dysregulated in immune microenvironment under pathological conditions. However, tumor-derived exosomes have been demonstrated to induce phenotypic and functional changes of MSCs, which can convert into cancer-associated cells (17). MSCs senescence can be found in SLE patients or lupus mice models. Changes of MSCs morphology and microstructure occur at the early stage in SLE patients with impaired immunosuppressive effects (18). Sun et al. have found that MSCs from SLE patients exhibit structural and functional defects, including slow growth, earlier aging and decreased vitality (18). In addition, a previous study has suggested abnormalities of multiple signaling pathways are involved in regulating actin cytoskeleton and cell cycling in BM-MSCs from SLE patients, such as MAPK and BMP/TGF- $\beta$ signaling pathways (19). SLE patients exist defective immune regulation of BM-MSCs from SLE patients, characteristic of down-regulated microRNA let-7f (20). The study by Che N et al. has shown that BM-MSCs from lupus-like mice and SLE patients are deficient in suppressing $B$ cell proliferation and differentiation (21). A previous study has shown that autologous MSCs from lupus patients are not effective in treating disease. However, whether it is possible to inhibit B cell proliferation seems to distinguish between effective MSCs and ineffective MSCs (22).

MSCs have immunomodulatory effects mainly through intercellular contact and paracrine pathways. MSC-EV is the main way for them to exert paracrine effects (23). MSC-EVs have stable membrane-like structure with a phospholipid bilayer. EVs contain substantial bioactive factors, such as nucleic acids, proteins and lipids. Some EVs delivering DNAs, mRNAs, circRNAs and lncRNAs have been demonstrated to play critical roles in regulating autoimmunity. MSC-EVs transfer bioactive molecules into the recipient cells mainly through three ways, namely, endocytosis, membrane fusion and specific receptor-ligand recognition. MSC-EVs can promote the transformation of inflammatory cell phenotypes (like M1 macrophages, DCs, Th1 and Th17 cells) into immunosuppressive phenotypes (like M2 macrophages, tolerance DCs and regulatory $\mathrm{T}$ cells) $(24,25)$. Accumulating studies have implicated that EVs derived non-coding RNAs play an important role in the pathogenesis of inflammatory and autoimmune diseases $(24,25)$. MSC-EVs have similar biological effects to MSCs, which are promising tools for tissue engineering and regenerative medicine $(15,26)$. MSC-EVs delivering molecules might not only be used as diagnostic biomarkers but therapeutic targets. Up to date, little has been known about the precise role of MSC-EVs derived bioactive molecules in SLE diseases.

MSC-EVs are important carriers for material transport and information exchange between MSC and other cells $(27,28)$. Exosomes are the most common type of EVs. They regulate $\mathrm{T}$ cells-, B cells- and other immune cells-mediated immune and inflammatory reactions (29, 30). MSC exosomes (MSC-Exo) encapsulating lipids, DNAs, RNAs and proteins are essential for intercellular communications (31). The role of MSC-Exo depends on its transferring bioactive molecules, such as proteins and RNAs (32). As a nano-scale natural carrier, exosomes can encapsulate and deliver bioactive substances produced by immune cells or tissue cells, such as nucleotides, peptides and lipids (33-35). MSC-Exo shows great potentials in intercellular information change between cells. Recently, non-coding RNAs have become a hot spot in oncology, rheumatology and other fields, such as circRNAs, lncRNAs, and miRNAs (36-40). Emerging evidence has elucidated that exosome-deriving miRNAs, circRNAs and other non-coding RNAs play important roles in SLE pathogenesis $(41,42)$. Therefore, noncoding RNA may serve as new diagnostic biomarkers or therapeutic targets for SLE. In this review, we have summarized currently available studies on the role of MSCs and MSCs-EVs in autoimmune diseases, primarily including SLE. These findings are useful for understanding SLE pathogenesis and exploring novel biomarkers for SLE diagnosis and treatment.

\section{IMMUNOREGULATORY EFFECTS OF MSCs AND MSC-EVs ON T CELLS}

Immune regulation dysfunction is the main cause for SLE (43). In particular, T cells play a key role in SLE pathogenesis. It has been illustrated that the interaction between MSCs and T cells is essential for maintaining immune balance. Various soluble immune regulatory factors, growth factors, non-coding RNA, proteins are involved in the interaction process through paracrine action (44). MSCs inhibit T cell proliferation and activation through EVs in a dose-dependent manner $(45,46)$. Accumulated studies have shown BM-MSCs inhibit $\mathrm{T}$ cells proliferation and differentiation by preventing them from entering $\mathrm{S}$ phase and G0/G1 phase of the cell cycle $(47,48)$. Fetal liver-derived MSCs (FL-MSCs) inhibit $\mathrm{CD}^{+}$and $\mathrm{CD} 8^{+} \mathrm{T}$ cells response and promote $\mathrm{CD} 4^{+} \mathrm{CD} 25^{+} \mathrm{Foxp}^{+}{ }^{+}$Tregs response (Table 1) (49). MSCs can induce T cells differentiation from proinflammatory state to anti-inflammatory state mainly by inhibiting lymphocyte proliferation and pro-inflammatory cytokines production (57). Thus, the extensive wealth of invitro data has suggested MSCs exert immunomodulatory effect on $\mathrm{T}$ cells and might participate in maintaining the balance of 
TABLE 1 | Mechanism of action with MSCs and EVs on T cells.

\begin{tabular}{|c|c|c|c|c|}
\hline Cell type & Immune cell & Mechanism & Effect & Reference \\
\hline FL-MSCs & $\begin{array}{l}\text { CD4+CD8+T cell and } \\
\text { Treg cell }\end{array}$ & - & $\begin{array}{l}\text { inhibit CD4+T cells, CD8+T cells and promote } \\
\text { Treg cells }\end{array}$ & $(49)$ \\
\hline MSC & Treg, Tfh & through an APC pathway & $\begin{array}{l}\text { promotes Treg cells and inhibits the generation } \\
\text { of Tfh }\end{array}$ & (49) \\
\hline MSC-EVs & Th1 cell & regulating glycolysis and cytokine signaling pathways & $\begin{array}{l}\text { inhibits T cell proliferation and Th1 } \\
\text { differentiation }\end{array}$ & (39) \\
\hline MSC-EVs & $\mathrm{CD}^{+}{ }^{+} \mathrm{T}$ cell & $\begin{array}{l}\text { EVs-encapsulating miR-23a-3p and post-transcriptionally regulated } \\
\text { TGF- } \beta \text { receptor } 2 \text { in T cells }\end{array}$ & suppressive Th1 differentiation & $(50)$ \\
\hline MSC-EXo & T cell & P27kip1/Cdk2 pathway & $\begin{array}{l}\text { suppressive activation T cell proliferation and } \\
\text { cell cycle arrest }\end{array}$ & $(51)$ \\
\hline MSC-EVs & T cell & increasing $\mathrm{IL}-10$ and TGF- $\beta$ & $\begin{array}{l}\text { promote T cells apoptosis and inhibit } \\
\text { proliferation }\end{array}$ & $(13)$ \\
\hline $\begin{array}{l}\text { AD-MSC } \\
\text { miR-10a }\end{array}$ & Th17/Treg cell & regulating Foxp $3^{+}$expression through TGF- $\beta$ pathway & $\begin{array}{l}\text { promote the differentiation of Th2 and Treg } \\
\text { from naive CD } 4^{+} T \text { cells }\end{array}$ & $(52)$ \\
\hline UC-MSCs & T cell & through the COX2/PGE2/NF- $\mathrm{kB}$ signaling pathway & $\begin{array}{l}\text { inhibiting } T \text { cell proliferation and DC } \\
\text { differentiation }\end{array}$ & (53) \\
\hline UC-MSCs & T cell & IFNGR1/JAK2/Stats signaling pathways, IFN- $\gamma /$ IDO axis & $\begin{array}{l}\text { suppressive T cell proliferation and promote } \\
\text { Treg function }\end{array}$ & $(54)$ \\
\hline AD-MSC & T cell & through regulating TGF- $\beta$ and PGE2 & regulate the Th17/Treg balance & $(55,56)$ \\
\hline
\end{tabular}

immune microenvironment. It has been documented that MSCs reduce the activation of antigen presenting cells (APCs) by producing soluble factors, such as indoleamine-2,3-dioxygenase (IDO), prostaglandin E2 (PGE2) and IL-10. MSC promotes the proportion of regulatory $\mathrm{T}$ (Treg) cells and inhibits the generation of $\mathrm{T}$ follicular helper (Tfh) cells through an APC pathway (58). It has been well established that MSCs can induce $\mathrm{T}$ cells differentiation into Treg and Th2 cells but inhibit Th17 and Tfh cells differentiation and immune response. Accordingly, MSCs might serve as a useful treatment strategy for autoimmune diseases, including SLE.

MSC-EVs exert immunomodulatory effects similar to MSCs. MSC-EVs inhibit T cell proliferation and Th1 differentiation by regulating glycolysis and cytokine signaling pathways (39). A previous study has suggested MSC-EVs promote $\mathrm{CD}^{+}{ }^{+} \mathrm{T}$ lymphocytes differentiation toward a regulatory phenotype by EVs-encapsulating miR-23a-3p and post-transcriptionally regulated TGF- $\beta$ receptor 2 in T cells (Table 1) (50). MSC-Exo suppresses the proliferation of $\mathrm{T}$ cells and induce cell cycle arrest through p27kip1/Cdk2 signaling pathway (Table 1) (51). MSCExo exerts immunosuppressive effects in autoimmune uveitis mice model by reducing $\mathrm{T}$ cell subsets and other inflammatory cells infiltration (59). Besides, MSCs-Exo enhances Treg generation in vitro and vivo (58). BM-MSC-EVs can prevent naive $\mathrm{T}$ cells differentiation into effector $\mathrm{T}$ cells and their activation (60). MSC-EVs promote the apoptosis of activated T cells, inhibit self-reactive lymphocytes proliferation, and produce more Tregs by increasing IL-10 and TGF- $\beta$ (13). These findings have suggested the biological functions of MSC-EVs are similar to MSC that can regulate immune cells growth and function. Accordingly, MSC-EVs might be a promising cell-free therapy in autoimmune diseases.

MiRNAs are endogenous single-stranded non-coding RNAs that regulate approximately $30-70 \%$ of human genes. They play an important role in innate and adaptive immune responses by influencing cell proliferation, differentiation and apoptosis (61). Accumulated data has shown that miRNAs disruption and dysfunction can interfere with immune response, stimulate inflammatory cytokines release, initiate autoantibodies production and promote autoimmune diseases occurrence, such as SLE $(62,63)$. The expression of miR-146a in SLE patients serum exosomes is significantly decreased, which can promote MSCs senescence by targeting TRAF6 and inhibiting $\mathrm{NF}-\kappa \mathrm{B}$ signaling pathway activation (Figure 1) $(64,65)$. Besides, exosomal miR-146a plays a key role in regulating innate immunity by targeting toll-like receptors (TLRs), tumor necrosis factor (TNF)-associated family (TNAF), and interleukin-1 receptor-associated kinase 1 (IRAK1) (Table 1) (66). Accordingly, circulating exosomes encapsulating miR-146a may be a key biomarker for SLE. The study by Bolandi Z et al. has suggested adipose-derived mesenchymal stem cell exosomes (AD-MSC-Exo) miR-10a promote the differentiation of Th2 and Treg from naive $\mathrm{CD}^{+} \mathrm{T}$ cells (52). AD-MSC-Exo miR10a can regulate Th17 and Treg differentiation by regulating Foxp $^{+}$expression through TGF- $\beta$ pathway (Table 1) (52). Taken together, MSCs carry molecular information of specific source cells and participate in intercellular communications.

Imbalance of Th1, Th2, Th17 and Treg results in inflammatory response and immune disorders in SLE $(20,67)$. Defective clearance of apoptotic cells (ACs) has been considered to be involved in the pathogenesis of SLE. It has been shown that human umbilical cord (UC) MSC possessed the ability to engulf ACs and then enhanced the immunosuppressive function by inhibiting $\mathrm{T}$ cell proliferation and DC differentiation through the COX2/PGE2/NF- $\kappa \mathrm{B}$ signaling pathway (Table 1) (53). MSCs have significant improvements of hematological ingredient by upregulating Treg and downregulating Th17 (68). Interestingly, BM-MSCs and UC-MSCs from SLE patients have a defect in 


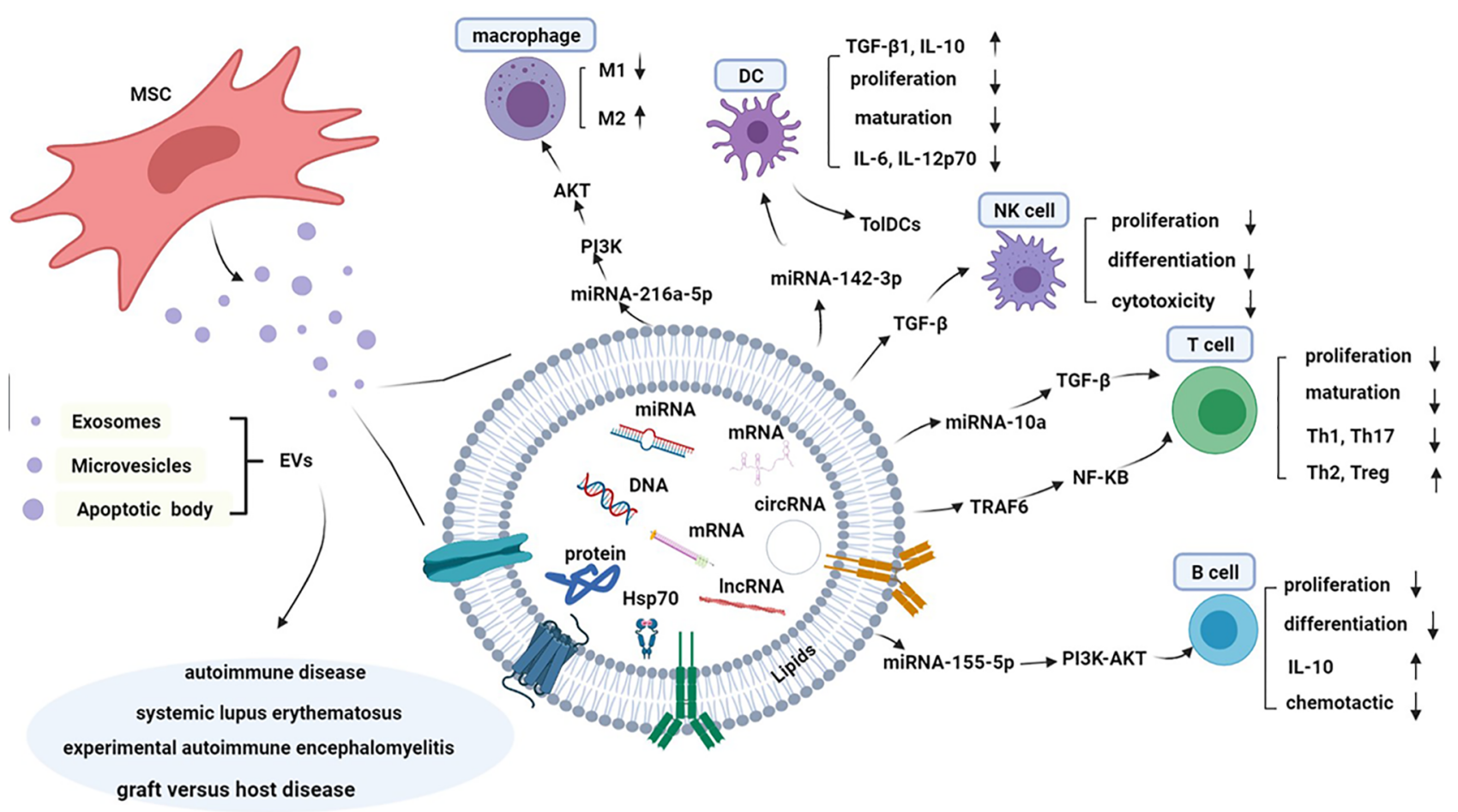

FIGURE 1 | Composition and mechanism of immunological tolerance of MSC-EVs in systemic lupus erythematosus. MSC-EVs are spheroidal shaped and two-layer lipid particles containing various types of protein, lipids, DNAs, non-coding RNAs, miRNAs, and mRNA, which cause genetic information exchange by various of signal pathway and reprogramming of the recipient cell. MSC-EVs can suppress the differentiation and proliferation of B cell by PI3K-AKT pathway, and reduce production of IL-10. Similarly, T cells play the suspensive role on the proliferation and maturation, while reduce production of Th17 and Th1, and improve function of Treg and Th2 through the TGF- $\beta / N F-\kappa B$ pathway. EVs can suppress the proliferation and maturation of DCs and induce tolerable DCs with low expression of costimulatory makers. Macrophages can transform to anti-inflammatory M2 phenotype after treating by MSC-EVs through the PI3K/AKT pathway. EVs can suppress the proliferation, differentiation and cytotoxicity of NK cells in a TGF- $\beta$ dependent manner. MSC-EVs play an important role in the pathogenesis of autoimmune diseases, including SLE, graft versus host disease, experimental autoimmune encephalomyelitis, etc.

IDO activity and secretion, which is an enzyme that mediates tryptophan degradation into immunosuppression metabolites (54). However, allogeneic UC-MSC can produce extremely amount of IDO to inhibit $\mathrm{T}$ cell proliferation through IFNGR1/JAK2/Stats signaling pathway (Table 1) (54). Moreover, MSC restores the immune balance via regulating TGF- $\beta$ and PGE2 and enhancing Treg/Th17 cells ratio in lupus mice $(55,56)$. In SLE patients, allogeneic UC-MSCs inhibit $\mathrm{T}$ cells response through IFN- $\gamma / \mathrm{IDO}$ axis (69), and induce more inducible Treg (iTreg) by generating antiinflammatory cytokines, such as TGF- $\beta 1$ (70, 71). Besides, BM-MSCs can alleviate lupus nephritis and improve mice survival rate by effectively inhibiting follicular helper $\mathrm{T}$ cell (Tfh) differentiation and IL-21 generation $(72,73)$.

\section{REGULATION OF MSCs AND MSC-EVs ON B CELLS}

Abundant activation and dysregulation of B cells is closely related to SLE pathogenesis. Pathogenic autoantibodies from B cells participate in SLE pathogenesis and mediate tissue damage, which are also involved in presenting antigens to self-reactive $\mathrm{T}$ cells (74). The activation of $\mathrm{B}$ cells leads to the production of a large number of autoreactivity autoantibodies involved in the disease process of SLE, including BAFF. A previous study has demonstrated that excessive expression of $\mathrm{miR}-152-3 \mathrm{p}$ is observed in SLE, resulting in increased BAFF Expression in SLE B-Cells by downregulating KLF5 (75). The study by Ma X et al. has shown that BM-MSC suppressed the excessive activation of B-cells via inhibiting BAFF production in MRL/ lpr mice (Table 2) (76). Belimumab, an anti-BAFF antibody, has already been used as a treatment target for SLE, which is approved by FDA for Lupus in 2011. A published study has reported that MSCs inhibit the proliferation of B lymphocytes by keeping the cell cycle in the G1 and G0 phases and impair plasma cell formation and immunoglobulin secretion $(81,83)$. Besides, MSCs can indirectly inhibit B cell differentiation, maturation, and plasma cell differentiation as well as antibody production through directly contacting with $\mathrm{T}$ cells (Table 2) (77). Moreover, MSCs inhibit the proliferation, excessive activation and maturation of $\mathrm{B}$ cells by depleting tryptophan in the inflammatory microenvironment of human body (Table 2) (78). Most interestingly, MSCs enhance increased regulation B (Breg) 
TABLE 2 | Mechanism of action with MSCs and EVs on B cell.

\begin{tabular}{|c|c|c|c|c|}
\hline Cell type & Immune cell & Mechanism & Effect & Reference \\
\hline BM-MSC & B cell & inhibition of BAFF production & suppress the excessive activation of B-cells & $(76)$ \\
\hline MSCs & B cell & directly contacting with $\mathrm{T}$ cells & inhibit B cell differentiation, maturation, & $(77)$ \\
\hline MSCs & B cell & $\begin{array}{l}\text { by depleting tryptophan in the inflammatory } \\
\text { microenvironment of human body }\end{array}$ & $\begin{array}{l}\text { inhibits the proliferation, excessive activation } \\
\text { and maturation of } B \text { cells }\end{array}$ & (78) \\
\hline MSC & Breg cell & through SDF-1-CXCR7 axis & increased regulation B (Breg) & $(77)$ \\
\hline $\begin{array}{l}\text { MSC-EVs } \\
\text { miRNA-155-5p }\end{array}$ & B cell & targeting PI3K/AKT signaling pathway & inhibit activation of B cell & (79) \\
\hline MSC & B cell & $\begin{array}{l}\text { increased expression of CCL2 by CCL2-MST1-mTOR-STAT1 } \\
\text { mediated metabolic signaling pathway }\end{array}$ & $\begin{array}{l}\text { prevent inhibition differentiation, proliferation, } \\
\text { and antibody secretion of B-cell }\end{array}$ & $(80)$ \\
\hline MSC & B cell & inhibit expression of maturation protein-1 & inhibit B cells terminal differentiation & (81) \\
\hline GMSCs & B cell & targeting of CD39-CD73 signaling pathway & suppressing B cells and produce autoantibodies & (82) \\
\hline
\end{tabular}

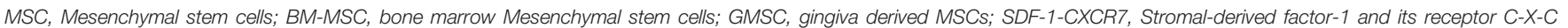

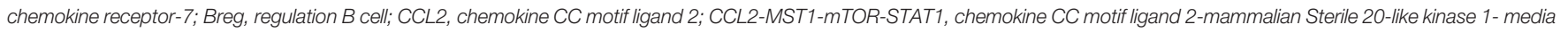
Time of Repair-signal transducerand activator of transcription 1.

cell through SDF-1-CXCR7 axis, which plays a key role in maintaining immune tolerance and inhibiting immune and inflammatory responses (84). MSCs affect B cells chemotaxis by inhibiting the production of immunoglobulin IgG, IgM and IgA and downregulating related ligands expression. As a result, MSCs regulate B cell response and mediate immune suppression, whereas the potential molecular mechanism warrants to be investigated.

The immunomodulatory effects of MSC on B Cells and plasma cells are associated with EVs delivering soluble factors $(85,86)$. MSC-exo inhibits the proliferation of T cells and B cells (Table 2) (29). It has been well documented that MSC-EVs delivering miRNA-155-5p reduce the activation of $\mathrm{B}$ cell cycle progression by targeting PI3K/AKT signaling pathway(Figure 1 and Table 2) (79). Nonetheless, more studies are warranted to further investigate the potential bioactive factors in MSC-EVs and their precise effects on immune cells function in SLE and other autoimmune diseases. Understanding the mechanisms of MSC-EVs in immune regulations may help for developing new therapeutic strategies for SLE.

It has been documented that toll-like receptor 7 (TLR7) is overexpressed in SLE, which drives autoreactive B cells activation and autoantibodies production through IFN- $\gamma$ signal pathway in SLE (87-89). MSC enhances IL-10 production by activating the extracellular signal-related kinase (ERK) signal but suppresses the generation of TNF- $\alpha$ by downregulating TLR-7/NF- $\kappa \mathrm{B}$ signal in murine macrophages (90). Intrinsic B cells with autoreactive $\mathrm{B}$ cell receptor (BCR) expression and long-lived plasma cells continuously producing autoantibodies are essential for the development of SLE (91). A previous study has implicated that MSCs derived from SLE patients have significantly reduced expression of CCL2 (21). Those MSCs prevent from the proliferation, differentiation, and antibody secretion of B-cell through CCL2-MST1-mTOR-STAT1 mediated metabolic signaling pathway (Table 2) (80). Elevated expression of IL-21 in serum of SLE patients promotes B cells differentiation, which thus leads to a large number of pathogenic autoantibodies aggravating SLE manifestations (92). MSCs exert inhibitory effects on the terminal differentiation of B cells through decreasing the expression of maturation protein-1 (Table 2) (81). In addition, human gingiva derived MSCs (GMSCs) directly suppress autoantibodies production and proteinuria and alleviate the histopathological progression of lupus nephritis through $\mathrm{CD}^{-} \mathrm{CD} 73$ signaling pathway (82). Thus, MSCs play a vital role in SLE pathogenesis by inhibiting B cells proliferation, differentiation and activation.

\section{REGULATORY EFFECTS OF MSCs AND MSC-EVs ON DENDRITIC CELLS}

DCs are the most important APCs, which are key cells in defending against infection and tumor. As APCs, DCs present exogenous antigens to secondary lymphoid tissues such as spleen and lymph nodes. In lupus nephritis, DC infiltrates the kidney to exacerbate inflammation. Shahir M et al. have found that MSCExo induces more tolerance DCs (tol-DCs) with low expression of costimulatory markers and IL- 6 , but increases the antiinflammatory cytokines of IL-10 and TGF- $\beta$ (Figure 1 and Table 3) (93). Moreover, the induced tol-DCs further promote the differentiation of regulatory $\mathrm{T}$ cells, which play a protective role in SLE (93). MSC pretreated with IFN- $\gamma$ inhibits DC maturation, activation, and antigen uptakes (Table 3) (94). Type I IFN is closely related to the severity of lupus nephritis, hematopoietic and central nervous system symptoms of SLE patients. Plasmacytoid DCs (pDCs) are considered to be the main source of type I IFN. Apart from pDCs, T cells, B cells and NK cells are also involved in IFN production in SLE (97). However, MSCs can inhibit the generation and function of pDCs (98). Accordingly, MSCs are ideal therapeutic way for SLE patients due to their inhibitory effects on pDCs and type I IFN. The regulatory effects of MSCs on DCs make them as promising treatment strategies for SLE patients.

Increasing studies have suggested the modulatory effects of MSC-EVs on immune cell functions. MSC-Exo transferring miRNA-155 and miRNA-146 have been found to regulate endotoxin-induced inflammatory response in DCs (99). Wang Y et al. have demonstrated that miR-142-3p was highly expressed in SLE, which induced pro-inflammatory moDCs involved in SLE pathogenesis (100). MSC-EVs are capable of attenuating DCs maturation and function. It has been found that some MSC-EVs derived miRNAs can decrease the expression of 
TABLE 3 | Mechanism of action with MSCs and EVs on DC cell.

\begin{tabular}{|c|c|c|c|c|}
\hline Cell type & Immune cell & Mechanism & Effect & Reference \\
\hline MSC-ExO & tol-DCs & $\begin{array}{l}\text { induces more tolerance DCs (tol-DCs) with low expression of } \\
\text { costimulatory markers }\end{array}$ & $\begin{array}{l}\text { increased anti-inflammatory cytokines IL-10 and TGF- } \beta \\
\text { expression but decreased IL- } 6 \text { expression, promotes the } \\
\text { differentiation of regulatory T cells }\end{array}$ & (93) \\
\hline MSC & DC & Combine with IFN- $\gamma$ & inhibits DC maturation, activation, and antigen uptakes & (94) \\
\hline MSC-Evs & DC & $\begin{array}{l}\text { expression of anti-inflammatory factors (TGF- } \beta 1 \text { and IL-10) } \\
\text { and reduce the generation of proinflammatory cytokines (L-6 } \\
\text { and } \mathrm{IL}-12 \mathrm{p} 70 \text { ) }\end{array}$ & attenuate DCs maturation and function & (95) \\
\hline UC-MSCs & $\mathrm{CD}_{1 \mathrm{C}^{+} \mathrm{DCs}}$ & upregulating serum FLT3L & Increased expression of CD1C ${ }^{+}$DCs & $(96)$ \\
\hline
\end{tabular}

MSC, Mesenchymal stem cells; MSC-EVs, MSC derived Extracellular Vesicles; MSC-Exo, MSC derived Exsome; UC-MSC, umbilical cord Mesenchymal stem cells; IL-10, interleukin 10; TGF- $\beta 1$, transforming growth factor- $\beta 1$; DC, Dendritic cells; NK, Natural killer; IFN- $\gamma$, interferon; IL-6, interleukin-6.

mature markers CD83, CD38 and CD80 and proinflammatory cytokines (IL-6 and IL-12p70) but promote the expression of anti-inflammatory factors (TGF- $\beta 1$ and IL-10) (Figure 1 and Table 3) (95).

A number of studies have shown that allogeneic BM-MSCs inhibit SLE inflammatory response by upregulating tolerance DCs. After transplantation of allogenic UC-MSCs, peripheral blood $\mathrm{CD}_{1} \mathrm{c}^{+}$DCs and serum FLT3L can be significantly upregulated in SLE patients, suggesting that UC-MSCs are useful for SLE treatment by inducing increased resistant $\mathrm{CD} 1 \mathrm{c}^{+} \mathrm{DCs}$ (96). Nonetheless, more future studies are warranted to elucidate the underlying mechanism involved in MSCs and DCs interactions in SLE.

\section{REGULATORY EFFECTS OF MSCs AND MSC-EVs ON NK CELLS}

NK cells primarily mediate natural immune response and also play a crucial role in the pathogenesis of SLE (Figure 1). In SLE patients, the number of NK cells is significantly reduced, whose cytotoxic activity and cytokine profile are impaired. NK cells with higher expression of granzyme $B$ are observed in active SLE patients, which can be further enhanced by IL-15 (101). Interactions between MSCs and NK cells are necessary for reducing NK cytotoxicity (102). A published study has confirmed that MSCs inhibit the activity of NK cells by regulating IDO and PGE2 (Table 4) (103, 104). BM-MSCs can inhibit NK cell proliferation induced by IL-12 and IL-21 but upregulate IFN- $\gamma$, IFN- $\alpha$, perforin and granzyme in NK cells
(Table 4) (105, 106). Besides, NK cells also exert regulatory effects on MSCs. NK cells promote MSCs recruitment and ROS production, which can downregulate MSCs activity (109). Interestingly, the sorted TLR4-positive MSC (TLR4 ${ }^{+}$MSC) has a strong inhibitory effect on NK cells by regulating the receptor NKG2D (107), suggesting the pivotal immunomodulatory effects of MSCs on NK cells.

Accumulating data has implicated that MSC-EVs inhibit NK cells proliferation by regulating G0 and G1 cell cycle phases (99). Exosomes from fetal liver MSCs (FL-MSCs) inhibit the proliferation, activation and cytotoxicity of NK cells by regulating TGF- $\beta$ (Table 4) (108). Activin A is a member of the TGF- $\beta$ superfamily. It has been demonstrated that UC-MSC produces a large amount of activin $\mathrm{A}$, which inhibits IFN- $\gamma$ production by downregulating T-bet in NK cells (110). However, whether MSC-EVs protect against SLE by inhibiting NK cells proliferation and function warrants to be further studied in the future. It is lacking substantial evidence to support the immunomodulatory effect of MSC-EVs on NK cells in lupus, either in animal models or in clinical studies. The precise effect and underlying mechanism of MSCs/MSC-EVs on NK cells in SLE warrant to be investigated in more future studies.

\section{REGULATORY EFFECTS OF MSCs AND MSC-EVs ON MACROPHAGES}

Imbalance of M1/M2 polarization and abnormal activation of macrophages are involved in the pathogenesis of SLE. Macrophages are responsible for clearing ACs. Increased ACs

TABLE 4 | Mechanism of action with MSCs and EVs on NK cell.

\begin{tabular}{|c|c|c|c|c|}
\hline Cell type & Immune cell & Mechanism & Effect & Reference \\
\hline MSC & NK cell & $\begin{array}{l}\text { regulating indoleamine-2, 3-dioxygenase (IDO) and } \\
\text { prostaglandin E2 (PGE2) }\end{array}$ & inhibit the activity of NK cells & $(103,104)$ \\
\hline BM-MSCs & NK cell & inhibit IL-12 and IL-21 & $\begin{array}{l}\text { Suppression NK cell proliferation but increase IFN- } \gamma \\
\text { and IFN- } \alpha \text { production }\end{array}$ & $(105,106)$ \\
\hline $\mathrm{TLR}^{+} \mathrm{MSC}$ & NK cell & - & inhibitory effect on NK cells and the receptor NKG2D & $(107)$ \\
\hline FL-MSC-EXO & NK cell & regulating TGF- $\beta$ & $\begin{array}{l}\text { inhibit the proliferation, activation and cytotoxicity of } \\
\text { NK cells }\end{array}$ & $(108)$ \\
\hline
\end{tabular}

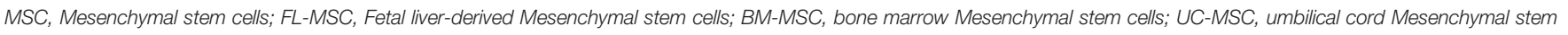


NKG2D, type II integral membrane protein; IFN- $\gamma$, interferon- $\gamma$; IFN- $\alpha$, interferon- $\alpha$. 
due to dysregulated macrophages will activate autoreactive B cells, thereby leading to abundant autoantibodies and immune complexes deposition in multiple organs and tissues (111). The polarization and activation of macrophages are different depending on certain microenvironmental conditions. It has been well established that MSCs effectively weaken the phagocytosis and antigen presentation of macrophages. Besides, MSCs can induce macrophage polarization to M2 phenotype through TGF- $\beta / A k t / F o x O 1$ pathway (Table 5) (112). Similarly, BM-MSCs can drive macrophages differentiation into anti-inflammatory phenotype M2, while they inhibit the differentiation of pro-inflammatory phenotype M1 (120). DNA methyltransferase 1 in SLE patients' peripheral blood mononuclear cells is increased. BM-MSC may downregulate the expression of methyltransferase 1 through the MEK/ERK signaling pathway, thereby inhibiting self-activated peripheral blood mononuclear cells from SLE patients (121). UC-MSC can affect M1/M2 balance by regulating macrophage metabolic pathways (Table 5) (113). Accordingly, MSCs play a critical role in maintaining M1/M2 balance in SLE.

A number of studies have shown that MSC-Exo has lower immunogenicity and can inhibit the development and progression of experimental autoimmune encephalomyelitis, traumatic spinal cord injury and diabetes animal models by regulating M1/M2 balance and Th17/Treg ratio (122-124). A previous study has shown that MSC-EVs enhance the antiinflammatory phenotype of regulatory macrophages by downregulating IL-23 and IL-22 and promoting inflammation remission (Table 5) (114). At the same time, AD-MSCs derived EVs are capable of inducing macrophage polarization toward M2 under hypoxia conditions (Table 5) (115). MSC-Exo exerts anti-inflammatory properties by promoting macrophages differentiation toward M2 through miR-223/pKNOX1 pathway (Table 5) (116). MSC-EVs delivering miR-216a-5p can be transferred to macrophages and induce M2 macrophages polarization through TLR4/NF- $\mathrm{KB} / \mathrm{PI} 3 \mathrm{~K} /$ Akt signaling cascade (Figure 1 and Table 5) (117). Interestingly, MSC-Exo attenuates myocardial ischemia-reperfusion injury by enhancing M2 macrophages polarization through miRNA-182 and its downstream target, namely, toll-like receptor 4 (TLR4) (125). Therefore, MSCs and MSC-EVs can effectively regulate macrophages polarization toward M2 and inhibit macrophages-mediated inflammatory response. However, little is known about the effect of MSCs and MSC-EVs on macrophages in SLE. It has been shown that MSC mediated macrophage polarization depends on the IL- 6 signaling pathway (126). UC-MSCs promote the proportion of CD206 ${ }^{+}$M2 cells and the phagocytic activity of macrophages in an IL- 6 dependent manner in SLE (127). Human UC-MSCs/exosomes attenuate the diffuse alveolar hemorrhage (DAH) induced inflammatory responses and alveolar hemorrhage through increasing M2 macrophage polarization in $\mathrm{DAH}$ patients or lupus mice (Table 5) $(118,119)$. All these findings have strongly suggested the pivotal role of MSC-EVs in macrophage polarization in SLE. MSC-Exo serves as a nanocarrier delivering bioactive molecules between immune cells and stem cells, which may be a promising treatment way for SLE.

During the past few years, immune metabolic disorders have been implicated in SLE pathogenesis, whereas the regulatory mechanism of MSC and MSC-EVs on the immune metabolic phenotype of macrophages and M1/M2 bias in SLE remains largely unclear. Blocking the reprogramming of macrophage metabolism and maintaining the balance of M1/M2 in the immune microenvironment would provide new insight into identifying valuable strategies for the biological treatment of SLE.

\section{POTENTIAL USE OF MSCs AND MSC-EVs IN SLE TREATMENT}

Current treatment strategies for SLE are mainly aimed at controlling and mitigating disease activity. Although Belimumab and Telitacicept have been approved for SLE treatment, the heterogeneity of SLE has led to the dilemma of current treatment status (128). Accordingly, identifying a more effective treatment strategy has become a top priority for SLE. Some studies have established that MSCs can attenuate the adverse effects of immunosuppressive drugs. A previous study

TABLE 5 | Mechanism of action with MSCs and EVs on macrophage.

\begin{tabular}{|c|c|c|c|c|}
\hline Cell type & Immune cell & Mechanism & Effect & Reference \\
\hline UC-MSC & macrophage & $\begin{array}{l}\text { regulating macrophage metabolic } \\
\text { pathways }\end{array}$ & affect M1/M2 balance & (113) \\
\hline MSC-ExO & macrophage & down-regulating IL-23 and IL-22 & $\begin{array}{l}\text { enhances the anti-inflammatory phenotype of macrophages, promoting } \\
\text { inflammation remission }\end{array}$ & (114) \\
\hline AD-MSCs & macrophage & - & toward M2 phenotype polarization & (115) \\
\hline MSC-EXO & macrophage & through miR-223/pKNOX1 pathway & promoting macrophages differentiation toward M2 & $(116)$ \\
\hline $\begin{array}{l}\text { UC-MSC/ } \\
\text { exosomes }\end{array}$ & macrophage & $\begin{array}{l}\text { increased the proportion of } \mathrm{M} 2 \\
\text { macrophage polarization }\end{array}$ & $\begin{array}{l}\text { attenuate diffuse alveolar hemorrhage (DAH) induced inflammatory responses } \\
\text { and alveolar hemorrhage }\end{array}$ & $(118,119)$ \\
\hline
\end{tabular}

MSC, Mesenchymal stem cells; MSC, Mesenchymal stem cells; MSC-EVs, MSC derived Extracellular Vesicles; MSC-exo, MSC derived Exsome; UC-MSC, umbilical cord Mesenchymal stem cells; AD-MSC, adipose MSC; TRAF6, IR7; IL-10, interleukin 10; IL-23, interleukin 23 ;L-22, interleukin 22; pKNOX1, PBX/knotted 1 homeobox 1; NF-KB, nuclear transcription factor-kappa B; PI3K, phosphoinositide 3-kinase; PGE2, Prostaglandin E2; TLR4, Toll-like Receptor 4; DAH, diffuse alveolar hemorrhage. 
has implicated that MSCs combination with immunosuppressive drugs display distinct effects on T cell activation and bias (129). They exert a suppressive effect on proinflammatory $\mathrm{T}$ cell subsets and promote the activation and function of anti-inflammatory Treg cells (129). Besides, accumulating evidence has suggested that mycophenolate mofetil (MMF) can selectively suppress B cells proliferation (74). Lee $\mathrm{HK}$ et al. have found that prednisone (PD) or MMF in combination with MSCs showed better therapeutic effect than single therapy in lupus-prone MRL/lpr mice (130). Combination of MSCs with PD or MMF can prolong the survival, decrease autoantibody levels and inflammatory cytokines in serum, and reduce the inflammatory cell infiltration in kidney and spleen in lupus mice (130). Moreover, immunosuppressants can influence MSC transplantation (MSCT) mediated immune responses and prolong the efficacy of transplanted MSCs (131). Accordingly, the combination of MSCs and immunosuppressants may become a more effectively therapeutic strategy for SLE.

MSCs are characterized by high self-renewal ability, rapid expansion in vivo and in vitro, and low immunogenicity. They can participate in immune response through two ways: paracrine effects and cell-cell interaction directly. In SLE patients, autologous MSCs are defective in immunomodulatory and regenerative functions. Allogeneic mesenchymal stem cell transplantation (MSCT) has brought new hope to cure severe SLE patients $(132,133)$. Reconstruction of immune tolerance and tissue regeneration and repair are necessary for SLE treatment. MSCs are easy for isolation and purification, which have good therapeutic effects in MRL/lpr and (NZB/NZW) F1 mice (134). Currently available animal studies have provided strong evidence for the therapeutic potentials of MSCs in SLE. The use of MSCs in treating SLE patients has also been reported in some previously published studies. The clinical symptoms of patients are significantly improved and the disease activity index is significantly decreased, when UC-MSCs are applied to the treatment of refractory and severe SLE patients.

MSCT is effective and safe in treating SLE patients and lupus animal models, even though Deng D et al. have shown that allogeneic UC-MSCs did not exert effects on SLE patients (135). However, a previous study has revealed that metformin-treated ADMSCs regulated the Th17/Treg balance in MRL/lpr mice, and metformin enhanced the immunomodulatory properties of $\mathrm{AD}$ MSCs through AMPK and STAT1 signal (Table 1) (136). It has been demonstrated that transplantation of human MSC can significantly inhibit disease progression in MRL/lpr mice (137). The study by Tang X et al. has suggested that dental pulp MSC (DPMSCs) could alleviate the disease symptoms of lupus-prone B6/lpr mice, especially reduce the kidney glomerular lesion and perivascular inflammation infiltration (138). MSCs are found to reduce proteinuria and serum anti-dsDNA levels, increase $\mathrm{C} 3$ and $\mathrm{C} 4$ levels and alter serum cytokine profiles by down-regulating the MyD88-NF-kB signaling pathway in NZBWF1 mice model (139). Most importantly, mounting clinical studies have shown intravenous infusion of UC-MSC is an available and safe practice in SLE treatment, which not only significantly declines SLE Disease Activity Index (SLEDAI) but also ameliorates renal function and systemic manifestations including hematopoietic and cutaneous systems in SLE patients $(140,141)$. It has been well documented that a repeated infusion of MSCs is feasible, and MSCT should be adopted again 6 months after the first time to avoid disease relapse in severe and refractory lupus patients $(140,142,143)$. LN patients get to renal remission 12 months after allogeneic MSCT, including obvious renal function amelioration in parallel with significantly improved glomerular filtration rate (144). Long-term serial administration of human AD-MSCs can help to ameliorate SLE without any adverse effects, which decreases the level of anti-doublestranded DNA antibodies but significantly increases IL-10 and Treg cells (145). Taken together, MSCT is a promising treatment strategy for SLE as evidenced by both animal experiments and clinical tests. However, the safety and efficacy need to be investigated in more future studies with large sample size. Last but not the least, the effect of MSCs derived EVs including exosomes in SLE is not clear yet, although they have been demonstrated to possess similar biological effects as MSCs in SLE (146).

\section{PERSPECTIVES}

Besides tissue repair and regeneration capacities, MSCs and MSEVs have strong anti-inflammatory and immunomodulatory effects. They can be ideal therapeutic strategy for SLE, particularly the refractory and severe SLE patients resistant to hormones and immunosuppressant drugs. Accumulating data has suggested MSC-EVs also have anti-inflammatory, antiapoptosis, pro-angiogenesis and immunomodulatory effects in inflammatory and autoimmune diseases by transferring bioactive constitutes to specific cells. Most importantly, MSC-EVs have much less immunogenicity but similar biological function with MSCs themselves, which act as a representative cell-free treatment way. Moreover, MSCs are demonstrated to possess tumorigenic potentials due to gene mutations, genetic instability as well as excessive proliferation and differentiation. Therefore, MSC-EVs may be a better choice for SLE treatment in future. Nevertheless, genetic modification, metabolic recombination, and other priming of MSCs in vitro should be considered before MSC/MSC-EVs application for SLE treatment. The standardized methods for MSC/MSC-EVs isolation, quantification and quality control should also be seriously considered before using MSC/MSC-EVs in treating SLE and other immune diseases. Lastly, the time of infusion, the appropriate dosage, the interval of treatment, and the longterm safety of MSC/MSC-EVs treatment in SLE warrant further clinical evaluations in more studies with high quality.

\section{AUTHOR CONTRIBUTIONS}

CY, JZ, and YT carried out literature research and reviewed all articles. JW, HL, JW, JY, and LZ helped to extract information. CY and SY wrote the paper. JS, CY, and DX revised the manuscript. SY and DX edited and submitted the article. All authors contributed to the article and approved the submitted version. 


\section{FUNDING}

This study is supported by funds from National Natural Science Foundation, China (82171790 and 82003042), Shandong Natural
Science Foundation (ZR2020KC001 and ZR2019QH012), Science and Technology Development Program of Weifang (2020TX084), and Weifang Science and Technology Development Program (2019GX031and 2019YX020).

\section{REFERENCES}

1. Justiz Vaillant AA, Goyal A, Bansal P, Varacallo M. Systemic Lupus Erythematosus. Treasure Island FL: StatPearls (2021).

2. Yan S, Wang W, Gao G, Cheng M, Wang X, Wang Z, et al. Key Genes and Functional Coexpression Modules Involved in the Pathogenesis of Systemic Lupus Erythematosus. J Cell Physiol (2018) 233:8815-25. doi: 10.1002/jcp.26795

3. Tsokos GC, Lo MS, Costa Reis P, Sullivan KE. New Insights Into the Immunopathogenesis of Systemic Lupus Erythematosus. Nat Rev Rheumatol (2016) 12:716-30. doi: 10.1038/nrrheum.2016.186

4. Yu F, Haas M, Glassock R, Zhao MH. Redefining Lupus Nephritis: Clinical Implications of Pathophysiologic Subtypes. Nat Rev Nephrol (2017) 13:48395. doi: 10.1038/nrneph.2017.85

5. Pons-Estel GJ, Alarcon GS, Scofield L, Reinlib L, Cooper GS. Understanding the Epidemiology and Progression of Systemic Lupus Erythematosus. Semin Arthritis Rheumatol (2010) 39:257-68. doi: 10.1016/j.semarthrit.2008.10.007

6. Gupta PK, Chullikana A, Rengasamy M, Shetty N, Pandey V, Agarwal V, et al. Efficacy and Safety of Adult Human Bone Marrow-Derived, Cultured, Pooled, Allogeneic Mesenchymal Stromal Cells (Stempeucel(R)): Preclinical and Clinical Trial in Osteoarthritis of the Knee Joint. Arthritis Res Ther (2016) 18:301. doi: 10.1186/s13075-016-1195-7

7. Van Pham P, Truong NC, Le PT, Tran TD, Vu NB, Bui KH, et al. Isolation and Proliferation of Umbilical Cord Tissue Derived Mesenchymal Stem Cells for Clinical Applications. Cell Tissue Bank (2016) 17:289-302. doi: 10.1007/s10561-015-9541-6

8. Romanov YA, Vtorushina VV, Dugina TN, Romanov AY, Petrova NV, Sukhikh GT. Human Umbilical Cord Tissue-Derived Multipotent Mesenchymal Stromal Cells Exhibit Maximum Secretory Activity in the Presence of Umbilical Cord Blood Serum. Bull Exp Biol Med (2020) 169:544-8. doi: 10.1007/s10517-020-04926-2

9. Calle A, Gutierrez-Reinoso MA, Re M, Blanco J, de la Fuente J, MonguioTortajada M, et al. Bovine Peripheral Blood MSCs Chemotax Towards Inflammation and Embryo Implantation Stimuli. J Cell Physiol (2021) 236:1054-67. doi: 10.1002/jcp.29915

10. Beeravolu N, McKee C, Alamri A, Mikhael S, Brown C, Perez-Cruet M, et al. Isolation and Characterization of Mesenchymal Stromal Cells From Human Umbilical Cord and Fetal Placenta. J Vis Exp (2017) 122:55224. doi: 10.3791/ 55224

11. Liu X, Xiang Q, Xu F, Huang J, Yu N, Zhang Q, et al. Single-Cell RNA-Seq of Cultured Human Adipose-Derived Mesenchymal Stem Cells. Sci Data (2019) 6:190031. doi: 10.1038/sdata.2019.31

12. Tomasello L, Mauceri R, Coppola A, Pitrone M, Pizzo G, Campisi G, et al. Mesenchymal Stem Cells Derived From Inflamed Dental Pulpal and Gingival Tissue: A Potential Application for Bone Formation. Stem Cell Res Ther (2017) 8:179. doi: 10.1186/s13287-017-0633-z

13. Kim H, Lee MJ, Bae EH, Ryu JS, Kaur G, Kim HJ, et al. Comprehensive Molecular Profiles of Functionally Effective MSC-Derived Extracellular Vesicles in Immunomodulation. Mol Ther (2020) 28:1628-44. doi: 10.1016/j.ymthe.2020.04.020

14. Aggarwal S, Pittenger MF. Human Mesenchymal Stem Cells Modulate Allogeneic Immune Cell Responses. Blood (2005) 105:1815-22. doi: 10.1182/blood-2004-04-1559

15. Fatima F, Ekstrom K, Nazarenko I, Maugeri M, Valadi H, Hill AF, et al. NonCoding RNAs in Mesenchymal Stem Cell-Derived Extracellular Vesicles: Deciphering Regulatory Roles in Stem Cell Potency, Inflammatory Resolve, and Tissue Regeneration. Front Genet (2017) 8:161. doi: 10.3389/ fgene.2017.00161

16. Ono M, Kosaka N, Tominaga N, Yoshioka Y, Takeshita F, Takahashi RU, et al. Exosomes From Bone Marrow Mesenchymal Stem Cells Contain a microRNA That Promotes Dormancy in Metastatic Breast Cancer Cells. Sci Signal (2014) 7:ra63. doi: 10.1126/scisignal.2005231

17. Lazennec G, Lam PY. Recent Discoveries Concerning the Tumor Mesenchymal Stem Cell Interactions. Biochim Biophys Acta (2016) 1866:290-9. doi: 10.1016/j.bbcan.2016.10.004

18. Sun LY, Zhang HY, Feng XB, Hou YY, Lu LW, Fan LM. Abnormality of Bone Marrow-Derived Mesenchymal Stem Cells in Patients With Systemic Lupus Erythematosus. Lupus (2007) 16:121-8. doi: 10.1177/0961203306075793

19. Tang Y, Ma X, Zhang H, Gu Z, Hou Y, Gilkeson GS, et al. Gene Expression Profile Reveals Abnormalities of Multiple Signaling Pathways in Mesenchymal Stem Cell Derived From Patients With Systemic Lupus Erythematosus. Clin Dev Immunol (2012) 2012:826182. doi: 10.1155/2012/ 826182

20. Geng L, Tang X, Wang S, Sun Y, Wang D, Tsao BP, et al. Reduced Let-7f in Bone Marrow-Derived Mesenchymal Stem Cells Triggers Treg/Th17 Imbalance in Patients With Systemic Lupus Erythematosus. Front Immunol (2020) 11:233. doi: 10.3389/fimmu.2020.00233

21. Che N, Li X, Zhang L, Liu R, Chen H, Gao X, et al. Impaired B Cell Inhibition by Lupus Bone Marrow Mesenchymal Stem Cells Is Caused by Reduced CCL2 Expression. J Immunol (2014) 193:5306-14. doi: 10.4049/ jimmunol.1400036

22. Collins E, Gu F, Qi M, Molano I, Ruiz P, Sun L, et al. Differential Efficacy of Human Mesenchymal Stem Cells Based on Source of Origin. J Immunol (2014) 193:4381-90. doi: 10.4049/jimmunol.1401636

23. Zhou J, Benito-Martin A, Mighty J, Chang L, Ghoroghi S, Wu H, et al. Retinal Progenitor Cells Release Extracellular Vesicles Containing Developmental Transcription Factors, microRNA and Membrane Proteins. Sci Rep (2018) 8:2823. doi: 10.1038/s41598-018-20421-1

24. Qiu G, Zheng G, Ge M, Wang J, Huang R, Shu Q, et al. Mesenchymal Stem Cell-Derived Extracellular Vesicles Affect Disease Outcomes via Transfer of microRNAs. Stem Cell Res Ther (2018) 9:320. doi: 10.1186/s13287-0181069-9

25. Harrell CR, Jovicic N, Djonov V, Arsenijevic N, Volarevic V. Mesenchymal Stem Cell-Derived Exosomes and Other Extracellular Vesicles as New Remedies in the Therapy of Inflammatory Diseases. Cells (2019) 8:1605. doi: $10.3390 /$ cells 8121605

26. Tsiapalis D, O’Driscoll L. Mesenchymal Stem Cell Derived Extracellular Vesicles for Tissue Engineering and Regenerative Medicine Applications. Cells (2020) 9:991. doi: 10.3390/cells9040991

27. Yeo RW, Lai RC, Zhang B, Tan SS, Yin Y, Teh BJ, et al. Mesenchymal Stem Cell: An Efficient Mass Producer of Exosomes for Drug Delivery. Adv Drug Delivery Rev (2013) 65:336-41. doi: 10.1016/j.addr.2012.07.001

28. Raposo G, Stoorvogel W. Extracellular Vesicles: Exosomes, Microvesicles, and Friends. J Cell Biol (2013) 200:373-83. doi: 10.1083/jcb.201211138

29. Khare D, Or R, Resnick I, Barkatz C, Almogi-Hazan O, Avni B. Mesenchymal Stromal Cell-Derived Exosomes Affect mRNA Expression and Function of B-Lymphocytes. Front Immunol (2018) 9:3053. doi: 10.3389/fimmu.2018.03053

30. Fathollahi A, Hashemi SM, Haji Molla Hoseini M, Yeganeh F. In Vitro Analysis of Immunomodulatory Effects of Mesenchymal Stem Cell- and Tumor Cell-Derived Exosomes on Recall Antigen-Specific Responses. Int Immunopharmacol (2019) 67:302-10. doi: 10.1016/j.intimp.2018.12.009

31. Kalluri R, LeBleu VS. The Biology, Function, and Biomedical Applications of Exosomes. Science (2020) 367:eaau6977. doi: 10.1126/science.aau6977

32. Toh WS, Lai RC, Zhang B, Lim SK. MSC Exosome Works Through a Protein-Based Mechanism of Action. Biochem Soc Trans (2018) 46:843-53. doi: 10.1042/BST20180079

33. Xu D, Song M, Chai C, Wang J, Jin C, Wang X, et al. Exosome-Encapsulated miR-6089 Regulates Inflammatory Response via Targeting TLR4. J Cell Physiol (2019) 234:1502-11. doi: 10.1002/jcp.27014

34. Wang JH, Liu XL, Sun JM, Yang JH, Xu DH, Yan SS. Role of Mesenchymal Stem Cell Derived Extracellular Vesicles in Autoimmunity: A Systematic Review. World J Stem Cells (2020) 12:879-96. doi: 10.4252/wjsc.v12.i8.879 
35. Yan S, Ren X, Yang J, Wang J, Zhang Q, Xu D. Exosomal miR-548c-5p Regulates Colorectal Cancer Cell Growth and Invasion Through HIF1A/ CDC42 Axis. Onco Targets Ther (2020) 13:9875-85. doi: 10.2147/ OTT.S273008

36. Xu Y, Deng W, Zhang W. Long Non-Coding RNA TUG1 Protects Renal Tubular Epithelial Cells Against Injury Induced by Lipopolysaccharide via Regulating microRNA-223. BioMed Pharmacother (2018) 104:509-19. doi: 10.1016/j.biopha.2018.05.069

37. Yan S, Liu G, Jin C, Wang Z, Duan Q, Xu J, et al. MicroRNA-6869-5p Acts as a Tumor Suppressor via Targeting TLR4/NF-kappaB Signaling Pathway in Colorectal Cancer. J Cell Physiol (2018) 233:6660-8. doi: 10.1002/jcp.26316

38. Liu W, Wang Z, Liu L, Yang Z, Liu S, Ma Z, et al. LncRNA Malat1 Inhibition of TDP43 Cleavage Suppresses IRF3-Initiated Antiviral Innate Immunity. Proc Natl Acad Sci USA (2020) 117:23695-706. doi: 10.1073/pnas. 2003932117

39. Xu H, Chen W, Zheng F, Tang D, Liu D, Wang G, et al. Reconstruction and Analysis of the Aberrant IncRNA-miRNA-mRNA Network in Systemic Lupus Erythematosus. Lupus (2020) 29:398-406. doi: 10.1177/ 0961203320908927

40. Zhang J, Liu Y, Shi G. The circRNA-miRNA-mRNA Regulatory Network in Systemic Lupus Erythematosus. Clin Rheumatol (2021) 40:331-9. doi: 10.1007/s10067-020-05212-2

41. Guo G, Wang H, Ye L, Shi X, Yan K, Lin K, et al. Hsa_circ_0000479 as a Novel Diagnostic Biomarker of Systemic Lupus Erythematosus. Front Immunol (2019) 10:2281. doi: 10.3389/fimmu.2019.02281

42. Lodde V, Murgia G, Simula ER, Steri M, Floris M, Idda ML. Long Noncoding RNAs and Circular RNAs in Autoimmune Diseases. Biomolecules (2020) 10:1044. doi: 10.3390/biom10071044

43. Sharabi A, Tsokos GC. T Cell Metabolism: New Insights in Systemic Lupus Erythematosus Pathogenesis and Therapy. Nat Rev Rheumatol (2020) 16:100-12. doi: 10.1038/s41584-019-0356-x

44. Ren G, Zhang L, Zhao X, Xu G, Zhang Y, Roberts AI, et al. Mesenchymal Stem Cell-Mediated Immunosuppression Occurs via Concerted Action of Chemokines and Nitric Oxide. Cell Stem Cell (2008) 2:141-50. doi: 10.1016/ j.stem.2007.11.014

45. Weiss ARR, Lee O, Eggenhofer E, Geissler E, Korevaar SS, Soeder Y, et al. Differential Effects of Heat-Inactivated, Secretome-Deficient MSC and Metabolically Active MSC in Sepsis and Allogenic Heart Transplantation. Stem Cells (2020) 38:797-807. doi: 10.1002/stem.3165

46. Cheng A, Choi D, Lora M, Shum-Tim D, Rak J, Colmegna I. Human Multipotent Mesenchymal Stromal Cells Cytokine Priming Promotes RAB27B-Regulated Secretion of Small Extracellular Vesicles With Immunomodulatory Cargo. Stem Cell Res Ther (2020) 11:539. doi: 10.1186/s13287-020-02050-6

47. Krampera M, Glennie S, Dyson J, Scott D, Laylor R, Simpson E, et al. Bone Marrow Mesenchymal Stem Cells Inhibit the Response of Naive and Memory Antigen-Specific T Cells to Their Cognate Peptide. Blood (2003) 101:3722-9. doi: 10.1182/blood-2002-07-2104

48. Glennie S, Soeiro I, Dyson PJ, Lam EW, Dazzi F. Bone Marrow Mesenchymal Stem Cells Induce Division Arrest Anergy of Activated T Cells. Blood (2005) 105:2821-7. doi: 10.1182/blood-2004-09-3696

49. Yu Y, Valderrama AV, Han Z, Uzan G, Naserian S, Oberlin E. Human Fetal Liver MSCs Are More Effective Than Adult Bone Marrow MSCs for Their Immunosuppressive, Immunomodulatory, and Foxp3(+) T Reg Induction Capacity. Stem Cell Res Ther (2021) 12:138. doi: 10.1186/s13287-021-02176-1

50. Franco da Cunha F, Andrade-Oliveira V, Candido de Almeida D, Borges da Silva T, Naffah de Souza Breda C, Costa Cruz M, et al. Extracellular Vesicles Isolated From Mesenchymal Stromal Cells Modulate CD4(+) T Lymphocytes Toward a Regulatory Profile. Cells (2020) 9:1059. doi: $10.3390 /$ cells 9041059

51. Lee S, Kim S, Chung H, Moon JH, Kang SJ, Park CG. Mesenchymal Stem Cell-Derived Exosomes Suppress Proliferation of T Cells by Inducing Cell Cycle Arrest Through P27kip1/Cdk2 Signaling. Immunol Lett (2020) 225:16-22. doi: 10.1016/j.imlet.2020.06.006

52. Bolandi Z, Mokhberian N, Eftekhary M, Sharifi K, Soudi S, Ghanbarian H, et al. Adipose Derived Mesenchymal Stem Cell Exosomes Loaded With miR10a Promote the Differentiation of Th17 and Treg From Naive CD4(+) T Cell. Life Sci (2020) 259:118218. doi: 10.1016/j.lfs.2020.118218
53. Zhang Z, Huang S, Wu S, Qi J, Li W, Liu S, et al. Clearance of Apoptotic Cells by Mesenchymal Stem Cells Contributes to Immunosuppression via PGE2. EBioMedicine (2019) 45:341-50. doi: 10.1016/j.ebiom.2019.06.016

54. Wang D, Feng X, Lu L, Konkel JE, Zhang H, Chen Z, et al. A CD8 T Cell/ Indoleamine 2,3-Dioxygenase Axis Is Required for Mesenchymal Stem Cell Suppression of Human Systemic Lupus Erythematosus. Arthritis Rheumatol (2014) 66:2234-45. doi: 10.1002/art.38674

55. Sun L, Akiyama K, Zhang H, Yamaza T, Hou Y, Zhao S, et al. Mesenchymal Stem Cell Transplantation Reverses Multiorgan Dysfunction in Systemic Lupus Erythematosus Mice and Humans. Stem Cells (2009) 27:1421-32. doi: $10.1002 /$ stem.68

56. Wang D, Huang S, Yuan X, Liang J, Xu R, Yao G, et al. The Regulation of the Treg/Th17 Balance by Mesenchymal Stem Cells in Human Systemic Lupus Erythematosus. Cell Mol Immunol (2017) 14:423-31. doi: 10.1038/ cmi.2015.89

57. Chiossone L, Conte R, Spaggiari GM, Serra M, Romei C, Bellora F, et al. Mesenchymal Stromal Cells Induce Peculiar Alternatively Activated Macrophages Capable of Dampening Both Innate and Adaptive Immune Responses. Stem Cells (2016) 34:1909-21. doi: 10.1002/stem.2369

58. Zhang B, Yeo RWY, Lai RC, Sim EWK, Chin KC, Lim SK. Mesenchymal Stromal Cell Exosome-Enhanced Regulatory T-Cell Production Through an Antigen-Presenting Cell-Mediated Pathway. Cytotherapy (2018) 20:687-96. doi: 10.1016/j.jcyt.2018.02.372

59. Bai L, Shao H, Wang H, Zhang Z, Su C, Dong L, et al. Effects of Mesenchymal Stem Cell-Derived Exosomes on Experimental Autoimmune Uveitis. Sci Rep (2017) 7:4323. doi: 10.1038/s41598-01704559-y

60. Del Fattore A, Luciano R, Pascucci L, Goffredo BM, Giorda E, Scapaticci M, et al. Immunoregulatory Effects of Mesenchymal Stem Cell-Derived Extracellular Vesicles on T Lymphocytes. Cell Transpl (2015) 24:2615-27. doi: 10.3727/096368915X687543

61. Xu HK, Chen LJ, Zhou SN, Li YF, Xiang C. Multifunctional Role of microRNAs in Mesenchymal Stem Cell-Derived Exosomes in Treatment of Diseases. World J Stem Cells (2020) 12:1276-94. doi: 10.4252/ wjsc.v12.i11.1276

62. Long H, Wang X, Chen Y, Wang L, Zhao M, Lu Q. Dysregulation of microRNAs in Autoimmune Diseases: Pathogenesis, Biomarkers and Potential Therapeutic Targets. Cancer Lett (2018) 428:90-103. doi: 10.1016/j.canlet.2018.04.016

63. Jin $\mathrm{F}, \mathrm{Hu} \mathrm{H}$, Xu M, Zhan S, Wang Y, Zhang H, et al. Serum microRNA Profiles Serve as Novel Biomarkers for Autoimmune Diseases. Front Immunol (2018) 9:2381. doi: 10.3389/fimmu.2018.02381

64. Li W, Liu S, Chen Y, Weng R, Zhang K, He X, et al. Circulating Exosomal microRNAs as Biomarkers of Systemic Lupus Erythematosus. Clinics (Sao Paulo) (2020) 75:e1528. doi: 10.6061/clinics/2020/e1528

65. Dong C, Zhou Q, Fu T, Zhao R, Yang J, Kong X, et al. Circulating Exosomes Derived-miR-146a From Systemic Lupus Erythematosus Patients Regulates Senescence of Mesenchymal Stem Cells. BioMed Res Int (2019) 2019:6071308. doi: 10.1155/2019/6071308

66. Labib DA, Shaker OG, El Refai RM, Ghoniem SA, Elmazny A. Association Between miRNA-146a and Polymorphisms of Its Target Gene, IRAK1, Regarding Susceptibility to and Clinical Features of Systemic Lupus Erythematous and Multiple Sclerosis. Lab Med (2019) 50:34-41. doi: 10.1093/labmed/lmy033

67. Talaat RM, Mohamed SF, Bassyouni IH, Raouf AA. Th1/Th2/Th17/Treg Cytokine Imbalance in Systemic Lupus Erythematosus (SLE) Patients: Correlation With Disease Activity. Cytokine (2015) 72:146-53. doi: 10.1016/j.cyto.2014.12.027

68. Li X, Wang D, Liang J, Zhang H, Sun L. Mesenchymal SCT Ameliorates Refractory Cytopenia in Patients With Systemic Lupus Erythematosus. Bone Marrow Transpl (2013) 48:544-50. doi: 10.1038/bmt.2012.184

69. Chen Y, Yu Q, Hu Y, Shi Y. Current Research and Use of Mesenchymal Stem Cells in the Therapy of Autoimmune Diseases. Curr Stem Cell Res Ther (2019) 14:579-82. doi: 10.2174/1574888X14666190429141421

70. Wang AYL, Loh CYY, Shen HH, Hsieh SY, Wang IK, Lee CM, et al. Human Wharton's Jelly Mesenchymal Stem Cell-Mediated Sciatic Nerve Recovery Is Associated With the Upregulation of Regulatory T Cells. Int J Mol Sci (2020) 21:6310. doi: $10.3390 /$ ijms 21176310 
71. Darlan DM, Munir D, Putra A, Jusuf NK. MSCs-Released TGFbetal Generate CD4(+)CD25(+)Foxp3(+) in T-Reg Cells of Human SLE PBMC. J Formos Med Assoc (2021) 120:602-8. doi: 10.1016/j.jfma.2020.06.028

72. Yang X, Yang J, Li X, Ma W, Zou H. Bone Marrow-Derived Mesenchymal Stem Cells Inhibit T Follicular Helper Cell in Lupus-Prone Mice. Lupus (2018) 27:49-59. doi: 10.1177/0961203317711013

73. Jang E, Jeong M, Kim S, Jang K, Kang BK, Lee DY, et al. Infusion of Human Bone Marrow-Derived Mesenchymal Stem Cells Alleviates Autoimmune Nephritis in a Lupus Model by Suppressing Follicular Helper T-Cell Development. Cell Transpl (2016) 25:1-15. doi: 10.3727/096368915X688173

74. Yap DYH, Chan TM. B Cell Abnormalities in Systemic Lupus Erythematosus and Lupus Nephritis-Role in Pathogenesis and Effect of Immunosuppressive Treatments. Int J Mol Sci (2019) 20:6231. doi: 10.3390/ ijms20246231

75. Luo S, Ding S, Liao J, Zhang P, Liu Y, Zhao M, et al. Excessive miR-152-3p Results in Increased BAFF Expression in SLE B-Cells by Inhibiting the KLF5 Expression. Front Immunol (2019) 10:1127. doi: 10.3389/fimmu.2019.01127

76. Ma X, Che N, Gu Z, Huang J, Wang D, Liang J, et al. Allogenic Mesenchymal Stem Cell Transplantation Ameliorates Nephritis in Lupus Mice via Inhibition of B-Cell Activation. Cell Transpl (2013) 22:2279-90. doi: 10.3727/096368912X658692

77. Rosado MM, Bernardo ME, Scarsella M, Conforti A, Giorda E, Biagini S, et al. Inhibition of B-Cell Proliferation and Antibody Production by Mesenchymal Stromal Cells Is Mediated by T Cells. Stem Cells Dev (2015) 24:93-103. doi: 10.1089/scd.2014.0155

78. Luk F, Carreras-Planella L, Korevaar SS, de Witte SFH, Borras FE, Betjes MGH, et al. Inflammatory Conditions Dictate the Effect of Mesenchymal Stem or Stromal Cells on B Cell Function. Front Immunol (2017) 8:1042. doi: 10.3389/fimmu.2017.01042

79. Adamo A, Brandi J, Caligola S, Delfino P, Bazzoni R, Carusone R, et al. Extracellular Vesicles Mediate Mesenchymal Stromal Cell-Dependent Regulation of B Cell PI3K-AKT Signaling Pathway and Actin Cytoskeleton. Front Immunol (2019) 10:446. doi: 10.3389/fimmu. 2019.00446

80. Yang L, Li N, Yang D, Chen A, Tang J, Jing Y, et al. CCL2 Regulation of MST1-mTOR-STAT1 Signaling Axis Controls BCR Signaling and B-Cell Differentiation. Cell Death Differ (2021) 28:2616-33. doi: 10.1038/s41418021-00775-2

81. Asari S, Itakura S, Ferreri K, Liu CP, Kuroda Y, Kandeel F, et al. Mesenchymal Stem Cells Suppress B-Cell Terminal Differentiation. Exp Hematol (2009) 37:604-15. doi: 10.1016/j.exphem.2009.01.005

82. Dang J, Xu Z, Xu A, Liu Y, Fu Q, Wang J, et al. Human Gingiva-Derived Mesenchymal Stem Cells Are Therapeutic in Lupus Nephritis Through Targeting of CD39(-)CD73 Signaling Pathway. J Autoimmun (2020) 113:102491. doi: 10.1016/j.jaut.2020.102491

83. Corcione A, Benvenuto F, Ferretti E, Giunti D, Cappiello V, Cazzanti F, et al. Human Mesenchymal Stem Cells Modulate B-Cell Functions. Blood (2006) 107:367-72. doi: 10.1182/blood-2005-07-2657

84. Qin Y, Zhou Z, Zhang F, Wang Y, Shen B, Liu Y, et al. Induction of Regulatory B-Cells by Mesenchymal Stem Cells Is Affected by SDF-1alphaCXCR7. Cell Physiol Biochem (2015) 37:117-30. doi: 10.1159/000430338

85. Fan L, Hu C, Chen J, Cen P, Wang J, Li L. Interaction Between Mesenchymal Stem Cells and B-Cells. Int J Mol Sci (2016) 17:650. doi: 10.3390/ ijms 17050650

86. Carreras-Planella L, Monguio-Tortajada M, Borras FE, Franquesa M. Immunomodulatory Effect of MSC on B Cells Is Independent of Secreted Extracellular Vesicles. Front Immunol (2019) 10:1288. doi: 10.3389/ fimmu.2019.01288

87. Wang T, Marken J, Chen J, Tran VB, Li QZ, Li M, et al. High TLR7 Expression Drives the Expansion of CD19(+)CD24(hi)CD38(hi) Transitional B Cells and Autoantibody Production in SLE Patients. Front Immunol (2019) 10:1243. doi: 10.3389/fimmu.2019.01243

88. Jenks SA, Cashman KS, Zumaquero E, Marigorta UM, Patel AV, Wang X, et al. Distinct Effector B Cells Induced by Unregulated Toll-Like Receptor 7 Contribute to Pathogenic Responses in Systemic Lupus Erythematosus. Immunity (2018) 49:725-39 e6. doi: 10.1016/j.immuni.2018.08.015

89. Chodisetti SB, Fike AJ, Domeier PP, Singh H, Choi NM, Corradetti C, et al. Type II But Not Type I IFN Signaling Is Indispensable for TLR7-Promoted
Development of Autoreactive B Cells and Systemic Autoimmunity. J Immunol (2020) 204:796-809. doi: 10.4049/jimmunol.1901175

90. Asami T, Ishii M, Fujii H, Namkoong H, Tasaka S, Matsushita K, et al. Modulation of Murine Macrophage TLR7/8-Mediated Cytokine Expression by Mesenchymal Stem Cell-Conditioned Medium. Mediators Inflamm (2013) 2013:264260. doi: 10.1155/2013/264260

91. Ma K, Du W, Wang X, Yuan S, Cai X, Liu D, et al. Multiple Functions of B Cells in the Pathogenesis of Systemic Lupus Erythematosus. Int J Mol Sci (2019) 20:6021. doi: 10.3390/ijms20236021

92. Feng Y, Yang M, Wu H, Lu Q. The Pathological Role of B Cells in Systemic Lupus Erythematosus: From Basic Research to Clinical. Autoimmunity (2020) 53:56-64. doi: 10.1080/08916934.2019.1700232

93. Shahir M, Mahmoud Hashemi S, Asadirad A, Varahram M, KazempourDizaji M, Folkerts G, et al. Effect of Mesenchymal Stem Cell-Derived Exosomes on the Induction of Mouse Tolerogenic Dendritic Cells. J Cell Physiol (2020) 235:7043-55. doi: 10.1002/jcp.29601

94. Wheat WH, Chow L, Kurihara JN, Regan DP, Coy JW, Webb TL, et al. Suppression of Canine Dendritic Cell Activation/Maturation and Inflammatory Cytokine Release by Mesenchymal Stem Cells Occurs Through Multiple Distinct Biochemical Pathways. Stem Cells Dev (2017) 26:249-62. doi: 10.1089/scd.2016.0199

95. Reis M, Mavin E, Nicholson L, Green K, Dickinson AM, Wang XN. Mesenchymal Stromal Cell-Derived Extracellular Vesicles Attenuate Dendritic Cell Maturation and Function. Front Immunol (2018) 9:2538. doi: $10.3389 /$ fimmu.2018.02538

96. Yuan X, Qin X, Wang D, Zhang Z, Tang X, Gao X, et al. Mesenchymal Stem Cell Therapy Induces FLT3L and $\mathrm{CD} 1 \mathrm{c}(+)$ Dendritic Cells in Systemic Lupus Erythematosus Patients. Nat Commun (2019) 10:2498. doi: 10.1038/ s41467-019-10491-8

97. Ethokic JM, Tomic SZ, Colic MJ. Cross-Talk Between Mesenchymal Stem/ Stromal Cells and Dendritic Cells. Curr Stem Cell Res Ther (2016) 11:51-65. doi: 10.2174/1574888X10666150904114035

98. Hackstein H, Tschipakow I, Bein G, Nold P, Brendel C, Baal N. ContactDependent Abrogation of Bone Marrow-Derived Plasmacytoid Dendritic Cell Differentiation by Murine Mesenchymal Stem Cells. Biochem Biophys Res Commun (2016) 476:15-20. doi: 10.1016/j.bbrc.2016.05.108

99. Di Trapani M, Bassi G, Midolo M, Gatti A, Kamga PT, Cassaro A, et al. Differential and Transferable Modulatory Effects of Mesenchymal Stromal Cell-Derived Extracellular Vesicles on T, B and NK Cell Functions. Sci Rep (2016) 6:24120. doi: 10.1038/srep24120

100. Wang Y, Liang J, Qin H, Ge Y, Du J, Lin J, et al. Elevated Expression of miR142-3p Is Related to the Pro-Inflammatory Function of Monocyte-Derived Dendritic Cells in SLE. Arthritis Res Ther (2016) 18:263. doi: 10.1186/ s13075-016-1158-z

101. Lin SJ, Kuo ML, Hsiao HS, Lee PT, Lee WI, Chen JY, et al. Cytotoxic Function and Cytokine Production of Natural Killer Cells and Natural Killer T-Like Cells in Systemic Lupus Erythematosis Regulation With Interleukin-15. Mediat Inflamm (2019) 2019:4236562. doi: 10.1155/2019/ 4236562

102. Sotiropoulou PA, Perez SA, Gritzapis AD, Baxevanis CN, Papamichail M. Interactions Between Human Mesenchymal Stem Cells and Natural Killer Cells. Stem Cells (2006) 24:74-85. doi: 10.1634/stemcells.2004-0359

103. Hu CD, Kosaka Y, Marcus P, Rashedi I, Keating A. Differential Immunomodulatory Effects of Human Bone Marrow-Derived Mesenchymal Stromal Cells on Natural Killer Cells. Stem Cells Dev (2019) 28:933-43. doi: 10.1089/scd.2019.0059

104. Chatterjee D, Marquardt N, Tufa DM, Beauclair G, Low HZ, Hatlapatka T, et al. Role of Gamma-Secretase in Human Umbilical-Cord Derived Mesenchymal Stem Cell Mediated Suppression of NK Cell Cytotoxicity. Cell Commun Signal (2014) 12:63. doi: 10.1186/s12964-014-0063-9

105. Najar M, Fayyad-Kazan M, Meuleman N, Bron D, Fayyad-Kazan H, Lagneaux L. Mesenchymal Stromal Cells of the Bone Marrow and Natural Killer Cells: Cell Interactions and Cross Modulation. J Cell Commun Signal (2018) 12:673-88. doi: 10.1007/s12079-018-0448-4

106. Gao L, OC M, Allen M, Liesveld J, McDavid A, Anolik JH, et al. Bone Marrow Mesenchymal Stem Cells From Patients With SLE Maintain an Interferon Signature During In Vitro Culture. Cytokine (2020) 132:154725. doi: 10.1016/j.cyto.2019.05.012 
107. Lu Y, Liu J, Liu Y, Qin Y, Luo Q, Wang Q, et al. TLR4 Plays a Crucial Role in MSC-Induced Inhibition of NK Cell Function. Biochem Biophys Res Commun (2015) 464:541-7. doi: 10.1016/j.bbrc.2015.07.002

108. Fan Y, Herr F, Vernochet A, Mennesson B, Oberlin E, Durrbach A. Human Fetal Liver Mesenchymal Stem Cell-Derived Exosomes Impair Natural Killer Cell Function. Stem Cells Dev (2019) 28:44-55. doi: 10.1089/scd.2018.0015

109. Cui R, Rekasi H, Hepner-Schefczyk M, Fessmann K, Petri RM, Bruderek K, et al. Human Mesenchymal Stromal/Stem Cells Acquire Immunostimulatory Capacity Upon Cross-Talk With Natural Killer Cells and Might Improve the NK Cell Function of Immunocompromised Patients. Stem Cell Res Ther (2016) 7:88. doi: 10.1186/s13287-016-0353-9

110. Chatterjee D, Marquardt N, Tufa DM, Hatlapatka T, Hass R, Kasper C, et al. Human Umbilical Cord-Derived Mesenchymal Stem Cells Utilize Activin-A to Suppress Interferon-Gamma Production by Natural Killer Cells. Front Immunol (2014) 5:662. doi: 10.3389/fimmu.2014.00662

111. Ma C, Xia Y, Yang Q, Zhao Y. The Contribution of Macrophages to Systemic Lupus Erythematosus. Clin Immunol (2019) 207:1-9. doi: 10.1016/ j.clim.2019.06.009

112. Liu F, Qiu H, Xue M, Zhang S, Zhang X, Xu J, et al. MSC-Secreted TGF-Beta Regulates Lipopolysaccharide-Stimulated Macrophage M2-Like Polarization via the Akt/FoxO1 Pathway. Stem Cell Res Ther (2019) 10:345. doi: 10.1186/ s13287-019-1447-y

113. Selleri S, Bifsha P, Civini S, Pacelli C, Dieng MM, Lemieux W, et al. Human Mesenchymal Stromal Cell-Secreted Lactate Induces M2-Macrophage Differentiation by Metabolic Reprogramming. Oncotarget (2016) 7:30193210. doi: 10.18632 /oncotarget. 8623

114. Hyvarinen K, Holopainen M, Skirdenko V, Ruhanen H, Lehenkari P, Korhonen M, et al. Mesenchymal Stromal Cells and Their Extracellular Vesicles Enhance the Anti-Inflammatory Phenotype of Regulatory Macrophages by Downregulating the Production of Interleukin (IL)-23 and IL-22. Front Immunol (2018) 9:771. doi: 10.3389/fimmu.2018.00771

115. Lo Sicco C, Reverberi D, Balbi C, Ulivi V, Principi E, Pascucci L, et al. Mesenchymal Stem Cell-Derived Extracellular Vesicles as Mediators of AntiInflammatory Effects: Endorsement of Macrophage Polarization. Stem Cells Transl Med (2017) 6:1018-28. doi: 10.1002/sctm.16-0363

116. He X, Dong Z, Cao Y, Wang H, Liu S, Liao L, et al. MSC-Derived Exosome Promotes M2 Polarization and Enhances Cutaneous Wound Healing. Stem Cells Int (2019) 2019:7132708. doi: 10.1155/2019/7132708

117. Xin D, Li T, Chu X, Ke H, Yu Z, Cao L, et al. Mesenchymal Stromal CellDerived Extracellular Vesicles Modulate Microglia/Macrophage Polarization and Protect the Brain Against Hypoxia-Ischemic Injury in Neonatal Mice by Targeting Delivery of miR-21a-5p. Acta Biomater (2020) 113:597-613. doi: 10.1016/j.actbio.2020.06.037

118. Chen X, Wei Q, Sun H, Zhang X, Yang C, Tao Y, et al. Exosomes Derived From Human Umbilical Cord Mesenchymal Stem Cells Regulate Macrophage Polarization to Attenuate Systemic Lupus ErythematosusAssociated Diffuse Alveolar Hemorrhage in Mice. Int J Stem Cells (2021) 14:331-40. doi: 10.15283/ijsc20156

119. Shi D, Wang D, Li X, Zhang H, Che N, Lu Z, et al. Allogeneic Transplantation of Umbilical Cord-Derived Mesenchymal Stem Cells for Diffuse Alveolar Hemorrhage in Systemic Lupus Erythematosus. Clin Rheumatol (2012) 31:841-6. doi: 10.1007/s10067-012-1943-2

120. Vasandan AB, Jahnavi S, Shashank C, Prasad P, Kumar A, Prasanna SJ. Human Mesenchymal Stem Cells Program Macrophage Plasticity by Altering Their Metabolic Status via a PGE2-Dependent Mechanism. Sci Rep (2016) 6:38308. doi: 10.1038/srep38308

121. Xiong H, Guo Z, Tang Z, Ai X, Qi Q, Liu X, et al. Mesenchymal Stem Cells Activate the MEK/ERK Signaling Pathway and Enhance DNA Methylation via DNMT1 in PBMC From Systemic Lupus Erythematosus. BioMed Res Int (2020) 2020:4174082. doi: 10.1155/2020/4174082

122. Liu W, Rong Y, Wang J, Zhou Z, Ge X, Ji C, et al. Exosome-Shuttled miR216a-5p From Hypoxic Preconditioned Mesenchymal Stem Cells Repair Traumatic Spinal Cord Injury by Shifting Microglial M1/M2 Polarization. J Neuroinflammation (2020) 17:47. doi: 10.1186/s12974-020-1726-7

123. Fan B, Li C, Szalad A, Wang L, Pan W, Zhang R, et al. Mesenchymal Stromal Cell-Derived Exosomes Ameliorate Peripheral Neuropathy in a Mouse Model of Diabetes. Diabetologia (2020) 63:431-43. doi: 10.1007/s00125019-05043-0
124. Riazifar M, Mohammadi MR, Pone EJ, Yeri A, Lasser C, Segaliny AI, et al. Stem Cell-Derived Exosomes as Nanotherapeutics for Autoimmune and Neurodegenerative Disorders. ACS Nano (2019) 13:6670-88. doi: 10.1021/ acsnano.9b01004

125. Zhao J, Li X, Hu J, Chen F, Qiao S, Sun X, et al. Mesenchymal Stromal CellDerived Exosomes Attenuate Myocardial Ischaemia-Reperfusion Injury Through miR-182-Regulated Macrophage Polarization. Cardiovasc Res (2019) 115:1205-16. doi: 10.1093/cvr/cvz040

126. Philipp D, Suhr L, Wahlers T, Choi YH, Paunel-Gorgulu A. Preconditioning of Bone Marrow-Derived Mesenchymal Stem Cells Highly Strengthens Their Potential to Promote IL-6-Dependent M2b Polarization. Stem Cell Res Ther (2018) 9:286. doi: 10.1186/s13287-018-1039-2

127. Deng W, Chen W, Zhang Z, Huang S, Kong W, Sun Y, et al. Mesenchymal Stem Cells Promote CD206 Expression and Phagocytic Activity of Macrophages Through IL-6 in Systemic Lupus Erythematosus. Clin Immunol (2015) 161:209-16. doi: 10.1016/j.clim.2015.07.011

128. Wallace DJ, Ginzler EM, Merrill JT, Furie RA, Stohl W, Chatham WW, et al. Safety and Efficacy of Belimumab Plus Standard Therapy for Up to Thirteen Years in Patients With Systemic Lupus Erythematosus. Arthritis Rheumatol (2019) 71:1125-34. doi: 10.1002/art.40861

129. Hajkova M, Hermankova B, Javorkova E, Bohacova P, Zajicova A, Holan V, et al. Mesenchymal Stem Cells Attenuate the Adverse Effects of Immunosuppressive Drugs on Distinct T Cell Subopulations. Stem Cell Rev Rep (2017) 13:104-15. doi: 10.1007/s12015-016-9703-3

130. Lee HK, Kim KH, Kim HS, Kim JS, Lee JH, Ji A, et al. Effect of a Combination of Prednisone or Mycophenolate Mofetil and Mesenchymal Stem Cells on Lupus Symptoms in MRL.Fas(lpr) Mice. Stem Cells Int (2018) 2018:4273107. doi: 10.1155/2018/4273107

131. Hwang JW, Myeong SH, Lee NH, Kim H, Son HJ, Chang JW, et al. Immunosuppressant Drugs Mitigate Immune Responses Generated by Human Mesenchymal Stem Cells Transplanted Into the Mouse Parenchyma. Cell Transpl (2021) 30:9636897211019025. doi: 10.1177/ 09636897211019025

132. Zhu Y, Feng X. Genetic Contribution to Mesenchymal Stem Cell Dysfunction in Systemic Lupus Erythematosus. Stem Cell Res Ther (2018) 9:149. doi: 10.1186/s13287-018-0898-x

133. Wang D, Zhang H, Liang J, Wang H, Hua B, Feng X, et al. A Long-Term Follow-Up Study of Allogeneic Mesenchymal Stem/Stromal Cell Transplantation in Patients With Drug-Resistant Systemic Lupus Erythematosus. Stem Cell Rep (2018) 10:933-41. doi: 10.1016/ j.stemcr.2018.01.029

134. Gu F, Molano I, Ruiz P, Sun L, Gilkeson GS. Differential Effect of Allogeneic Versus Syngeneic Mesenchymal Stem Cell Transplantation in MRL/lpr and (NZB/NZW)F1 Mice. Clin Immunol (2012) 145:142-52. doi: 10.1016/ j.clim.2012.08.012

135. Deng D, Zhang P, Guo Y, Lim TO. A Randomised Double-Blind, PlaceboControlled Trial of Allogeneic Umbilical Cord-Derived Mesenchymal Stem Cell for Lupus Nephritis. Ann Rheum Dis (2017) 76:1436-9. doi: 10.1136/ annrheumdis-2017-211073

136. Jang SG, Lee J, Hong SM, Kwok SK, Cho ML, Park SH. Metformin Enhances the Immunomodulatory Potential of Adipose-Derived Mesenchymal Stem Cells Through STAT1 in an Animal Model of Lupus. Rheumatol (Oxford) (2020) 59:1426-38. doi: 10.1093/rheumatology/kez631

137. Zhou K, Zhang H, Jin O, Feng X, Yao G, Hou Y, et al. Transplantation of Human Bone Marrow Mesenchymal Stem Cell Ameliorates the Autoimmune Pathogenesis in MRL/lpr Mice. Cell Mol Immunol (2008) 5:417-24. doi: 10.1038/cmi.2008.52

138. Tang X, Li W, Wen X, Zhang Z, Chen W, Yao G, et al. Transplantation of Dental Tissue-Derived Mesenchymal Stem Cells Ameliorates Nephritis in Lupus Mice. Ann Transl Med (2019) 7:132. doi: 10.21037/atm.2019.02.41

139. Wu KH, Cheng CC, Li JP, Weng TF, Yang SF, Pan HH, et al. Toll-Like Receptor Signalling Associated With Immunomodulation of Umbilical Cord-Derived Mesenchymal Stem Cells in Mice With Systemic Lupus Erythematosus. Lupus (2020) 29:165-75. doi: 10.1177/0961203319898532

140. Wang D, Zhang H, Liang J, Li X, Feng X, Wang H, et al. Allogeneic Mesenchymal Stem Cell Transplantation in Severe and Refractory Systemic Lupus Erythematosus: 4 Years of Experience. Cell Transpl (2013) 22:2267-77. doi: 10.3727/096368911X582769c 
141. Zhou T, Li HY, Liao C, Lin W, Lin S. Clinical Efficacy and Safety of Mesenchymal Stem Cells for Systemic Lupus Erythematosus. Stem Cells Int (2020) 2020:6518508. doi: 10.1155/2020/6518508

142. Wang D, Li J, Zhang Y, Zhang M, Chen J, Li X, et al. Umbilical Cord Mesenchymal Stem Cell Transplantation in Active and Refractory Systemic Lupus Erythematosus: A Multicenter Clinical Study. Arthritis Res Ther (2014) 16:R79. doi: 10.1186/ar4520

143. Sun L, Wang D, Liang J, Zhang H, Feng X, Wang H, et al. Umbilical Cord Mesenchymal Stem Cell Transplantation in Severe and Refractory Systemic Lupus Erythematosus. Arthritis Rheumatol (2010) 62:2467-75. doi: 10.1002/art.27548

144. Gu F, Wang D, Zhang H, Feng X, Gilkeson GS, Shi S, et al. Allogeneic Mesenchymal Stem Cell Transplantation for Lupus Nephritis Patients Refractory to Conventional Therapy. Clin Rheumatol (2014) 33:1611-9. doi: 10.1007/s10067-014-2754-4

145. Choi EW, Shin IS, Park SY, Park JH, Kim JS, Yoon EJ, et al. Reversal of Serologic, Immunologic, and Histologic Dysfunction in Mice With Systemic Lupus Erythematosus by Long-Term Serial Adipose Tissue-Derived Mesenchymal Stem Cell Transplantation. Arthritis Rheumatol (2012) 64:243-53. doi: 10.1002/art.33313

146. Sharma J, Hampton JM, Valiente GR, Wada T, Steigelman H, Young MC, et al. Therapeutic Development of Mesenchymal Stem Cells or Their
Extracellular Vesicles to Inhibit Autoimmune-Mediated Inflammatory Processes in Systemic Lupus Erythematosus. Front Immunol (2017) 8:526. doi: 10.3389/fimmu.2017.00526

Conflict of Interest: The authors declare that the research was conducted in the absence of any commercial or financial relationships that could be construed as a potential conflict of interest.

Publisher's Note: All claims expressed in this article are solely those of the authors and do not necessarily represent those of their affiliated organizations, or those of the publisher, the editors and the reviewers. Any product that may be evaluated in this article, or claim that may be made by its manufacturer, is not guaranteed or endorsed by the publisher.

Copyright $\odot 2021$ Yang, Sun, Tian, Li, Zhang, Yang, Wang, Zhang, Yan and Xu. This is an open-access article distributed under the terms of the Creative Commons Attribution License (CC BY). The use, distribution or reproduction in other forums is permitted, provided the original author(s) and the copyright owner $(s)$ are credited and that the original publication in this journal is cited, in accordance with accepted academic practice. No use, distribution or reproduction is permitted which does not comply with these terms. 